Научная статья

УДК $821.161 .1+82.091$

DOI 10.18101/2686-7095-2021-3-38-44

\title{
ЛЕКСИКОГРАФИЧЕСКОЕ ПРЕДСТАВЛЕНИЕ ЛЕКСЕМЫ «САПОГИ» В ИДИОГЛОССАРИИ ДОСТОЕВСКОГО
}

\author{
(C) Ружицкий Игорь Васильевич \\ доктор филологических наук, профессор \\ кафедры дидактической лингвистики \\ и теории преподавания русского языка как иностранного, \\ Московский государственный университет имени М. В. Ломоносова \\ Россия, 119991, г. Москва, ул. Ленинские горы, д. 1, стр. 51 \\ konnitie@mail.ru
}

\author{
(C) Коробова Марина Михайловна \\ научный сотрудник отдела экспериментальной лексикографии, \\ Институт русского языка имени В. В. Виноградова РАН \\ Россия, 119019, г. Москва, ул. Волхонка, 18/2 \\ mmkor1955@yandex.ru
}

\begin{abstract}
Аннотация. В статье показана возможность словарного описания лексемы сапоги, функционирующей в текстах Достоевского в качестве идиоглоссы, т. е. слова, отражающего особенности авторского идиостиля. Кратко изложена система лексикографических параметров, лежащая в основе построения Словаря языка Достоевского, его базовой части - Идиоглоссария, в которую входит паратаксис и гипотаксис описываемого слова, употребление в одном контексте с однокоренными словами, символическое употребление, состав текстового ассоциативного поля и др. Выделены наиболее релевантные для лексикографического представления идиоглоссы сапоги параметры, проиллюстрированные примерами из текстов Достоевского. Сделаны выводы о возможностях интерпретации полученных лексикографических данных, прежде всего касательно символической и эмблематической функций описываемой лексемы, а также соответствующего текстового ассоциативного поля, ядром которого она является.
\end{abstract}

Ключевые слова: Достоевский, словарь языка писателя, идиоглоссарий, структура словарной статьи, лексикографическая параметризация, идиоглосса.

\section{Для цитирования}

Ружицикй И. В., Коробова М. М. Лексикографическое представление лексемы «сапоги» в Идиоглоссарии Достоевского // Вестник Бурятского государственного университета. Филология. 2021. Вып. 3. С. 38-44.

Система параметров Словаря языка Ф. М. Достоевского (далее - СЯД) [СЯД, 2008-2021] была обозначена Ю. Н. Карауловым и Е. Л. Гинзбургом [Караулов, 2001] и конкретизирована нами в предисловии ко второму и пятому томам Идиоглоссария [СЯД 2010; 2021], а также в [Ружицкий, 2015; Коробова и др., 2016]. Она предполагает учет следующих лексикографических показателей:

- параметры корпуса словарной статьи:

1) вход-идиоглосса, слово, раскрывающее особенности авторского идиостиля; 2) частота употребления описываемого слова (общая, в произведениях художествен- 
И. В. Ружицкий, М. М. Коробова. Лексикографическое представление лексемы «сапоги» в Идиоглоссарии Достоевского

ной прозы, в публицистических текстах, в личных письмах и в деловых письмах); 3) дефиниция; 4) иллюстрация (обязательно из всех периодов творчества писателя, начиная с первого употребления, и из всех жанров); 5) авторство иллюстрации (сам Достоевский, персонаж и др.); 6) адрес; 7) хронология; 8) жанр; 9) употребление в составе фразеологической единицы, 10) употребление в составе имени собственного; 11) словоуказатель;

\section{- параметры комментария словарной статьи:}

1) подчинительные связи, гипотаксис (СЧТ1); 2) сочинительные связи, паратаксис (СЧТ2); 3) нестандартная сочетаемость (НСТ); 4) морфологические особенности, например, использование идиоглоссы в искаженной русской речи и др. (МРФ); 5) словообразовательное гнездо (СЛБР); 6) употребление однокоренных с описываемым слов в одном узком контексте (КОМБ2); 7) употребление описываемого слова в разных значениях в одном узком контексте (КОМБ1); 8) неразличение значений (НРЗН); 9) игровое употребление (ИГРВ); 10) тропеическое употребление (ТРП); $11)$ употребление в ироническом контексте (ИРОН); 12) употребление в составе высказывания афористического типа (АФРЗ); 13) автонимное употребление (АВТН); $14)$ символическое употребление (СМВЛ); 15) употребление в составе чужой речи (ЧЖР); 16) ассоциативные связи слова (АССЦ). В СЯД помимо комментария широко используется такая рубрика, как примечания - к слову, к какому-то из его значений, к той или иной зоне комментария, в которые входит, например, фиксация употребления описываемой идиоглоссы в противопоставлении, в повторе, в зевгме и т. д.

Для лексемы сапог, сапоги релевантной является большая часть указанных лексикографических показателей, что, в частности, аргументирует ее принадлежность к идиоглоссам.

Представим данную словарную статью, вошедшую в пятый том Идиоглоссария [СЯД, 2021], в сокращенном виде, исключив большую часть иллюстративного материала - примеров употребления лексемы сапог, сапоги в текстах Достоевского и сопроводив ее краткими комментариями.

САПОГ, САПОГИ <222:187,21,14,->

Важно отметить, что частота употребления слова далеко не всегда является определяющим фактором при отнесении слова к идиоглоссам, однако частотные показатели лексемы сапог, сапоги являются значимыми, общее количество словоупотреблений (222) существенно превышает статистически среднее, присущее идиоглоссам (100). Большинство словоупотреблений приходится на произведения художественной прозы (187) и, как это хорошо видно из словоуказателя ниже, на первые произведения Достоевского - «Бедные люди» (БЛ) и «Двойник» (Дв), а также на романы третьего периода творчества писателя - «Преступление и наказание» (ПН), «Бесы» (Бс) и «Братья Карамазовы» (БрК и БКа) (здесь и далее номера страниц произведений Достоевского даются по: [Достоевский, 1972-1990]):

Словоуказатель (для произведений художественной прозы) сапог БЛ 81 Дв 142 ГП 249 чЖ 76 СС 20, 96 3М 40, 40, 73 ПН 27, 72, 72, 102 Ид 9 ВМ 57, 99 Бс 213, 483 Пд 27 БрК 66, 104, 380[22] сапога БЛ 69 Дв 139 СС 75 ПН 72 Пд 119, 345[6] сапогам БЛ 54 ПН 102[2] сапогами БЛ 53, 54, 54 Дв 116, 124, 133 УО 171 ЗП 147 ПН 69 Бс 302, 384 БКа 82[12] сапогах БЛ 43, 76, 76, 85 Дв 217 ГП 259 НН 153 ДС 363 УО 2653375 ПН 66, 115, 206 Ид 11, 96 ВМ 95 Бс 242, 242, 285, 354 Пд 148, 343 БрК 160, 205, 340, 468 БКа 16, 101, 165[29] сапоге БЛ 62 Бс 321 БрК 162[3] сапоги БЛ 35, 39, 54, 54, 62, 62, 62, 63, 74, 74, 76, $76,81,88,89,89,89,89,95,95,95$ Дв 111, 111, 111, 112, 112, 135, 135, 140, 168, 208, 217, 217 ГП 259 Пл 12, 12 ДС 298, 298, 331, 351 СС 50, 85, 168 УО 265 3М 28, 44, 48, 53, 58, 64, 72, 131, 187 СА 353353 ЗП 140 Кр 198 ПН 11, 18, 44, 66, 66, 102, 102, 130, 132, 320 Ид 
$115,163,374$ Бс 23, 27, 111, 111, 372, 411, 411, 427, 482 Пд 27, 69, 69, 98 БрК 90, 90, 116, 146, 428, 466, 479[90] сапоги-то БЛ 72[1] сапогов БЛ 47, 76, 95, 95 Дв 187, 215, 215 ГП 243 СС 84, 85 3М 39 Кр 206 ПН 99 Бс 510[14] сапогом Ср 46 ЗМ 114, 190 Пд 345, 378 БрК 74[6] сапогу 3М 133 Бс 205[2].

Следует отметить, что относительная частота употребление лексемы canoz, caпоги в «Бедных людях» и в «Двойнике» значительно выше, чем в других текстах Достоевского.

Дефиниция вполне стандартная, аналогичные определения значения слова canoz, сапоги мы встречаем в большинстве толковых словарей русского языка: 'вид обуви, обычно с высокими голенищами’, а в качестве иллюстраций предлагаются, например, такие контексты:

(из произведений художественной прозы):

[Доброселова] Покровский своими советами отучал понемногу старика от дурных наклонностей, и как только видел его раза три сряду в трезвом виде, то при первом посещении давал ему на прощанье по четвертачку, по полтинничку или больше. Иногда покупал ему сапоги, галстух или жилетку (Бедные люди, 35); Тут в недоумении своем опустил он [Голядкин] глаза в землю и, к крайнему своему изумлению, увидел на сапогах его превосходительства значительное белое пятно. «Неужели лопнули?» - подумал господин Голядкин. Вскоре, однако ж, господин Голядкин открыл, что сапоги его превосходительства вовсе не лопнули, а только сильно отсвечивали, - феномен, совершенно объяснившийся тем, что сапоги были лакированные и сильно блестели. «Это называется блик, - подумал герой наш, - особенно же сохраняется это название в мастерских художников; в других же местах этот отсвет называется светльлм ребром» (Двойник, 217).

(из публицистических текстов — статей и «Дневника писателя»):

Но ведь и тут герой наш [анонимный ругатель] выдержал характер вполне, - ибо для чего он бросился к ногам генерала? Конечно, от болезни, конечно, от мнительности, но главное и от того, что он, - и струсивший, и униженный, и себя во всем обвиняющий, - а все же мечтал по-прежнему, как всеупоенный самомнением дурачок, что, может быть, его превосходительство, выслушав его, и все же, так сказать, пораженный его гением, - раскроет обе руки свои, которыми он столь много подписывает на пользу отечества бумаг, и заключит его в свои объятия: «<..> Но приди, приди на грудь мою, и вместе со мною раздели пост мой и мы... и мы перевернем департамент!» Но так не случилось, и потом, долго спустя, в позоре и в унижении, вспоминая о пинке носком генеральского сапога, пришедшегося ему прямо тогда в лицо, он почти искренно обвинял судьбу и людей: «Раз, дескать, в жизни моей я раскрыл людям мои объятия вполне, и что же удостоился получить?».

(из личных писем):

За № 2 р. цены против летних, сами говорят, что увеличены, и гостиница во всех отношениях ветховата, но все-таки, может быть, даже лучше иных других. Денег со мной 32 руб., и, однако, сегодня же надо купить сапоги, потому что мои до того дорогою разорвались, что даже нехорошо, если зайти в них к Некрасову и Мещерскому.

В корпусе словарной статьи зафиксированы также три случая употребления слова сапоги в составе фразеологических единиц и их модификаций, или трансформаций: отрясу прах с моих сапогов (отрясти прах со своих ног), С головы до сапог (с головы до ног), сапоги каши просят.

Такое лексикографическое представление идиоглоссы сапог, сапоги у Достоевского, конечно, не охватывает всех оттенков значения и употребления этого слова, его значимости в авторском тезаурусе, которая эксплицируется посредством многопараметрового комментария, в данном случае включающего в себя следующие зоны (приведем лишь несколько примеров):

АФР3 [Настасья Раскольникову] Без сапог нельзя детей учить (Преступление и наказание, 27); [Разумихин Лужину] Деловитость в сапогах ходит (там же, 115); [Шатов 
И. В. Ружицкий, М. М. Коробова. Лексикографическое представление лексемы «сапоги» в Идиоглоссарии Достоевского

Хроникеру] Наш русский либерал прежде всего лакей и только и смотрит, как бы комунибудь сапоги вычистить. - | Какие сапоги? Что за аллегория? (Бесы, 111); [Версилов Аркадию] <..> действительность и всегда отзывается сапогом, даже при самом ярком стремлении к идеалу $<\ldots>$ (Подросток, 378).

КОМБ2 [Версилов Аркадию] Я был другой культуры, и сердце мое не допускало того. Эта неблагодарность, с которою они расставались с идеей, эти свистки и комки грязи мне были невыносимы. Сапожность процесса пугала меня. Впрочем, действительность и всегда отзывается сапогом, даже при самом ярком стремлении к идеалу <...> (Подросток, 378).

СМВЛ:

Наиболее существенная для идиоглоссы сапог, сапоги зона комментария -

СМВЛЛ (1) Символическая функция идиоглоссы сапог, сапоги реализуется прежде всего в романе «Бедные люди», при этом во многих случаях эта функция обладает определенным синкретизмом, объединяет как общекультурные смыслы (сапоги символ достатка, власти, положения в обществе, в основном - «маленького человека»), так и индивидуально-авторские (сапоги - противоположность обыденноматериального, недостойного человека, духовному), что наиболее ярко прослеживается в снах Девушкина о сапогах: «Враги-то мои, злые-то языки эти все что заговорят, когда без шинели пойдешь? Ведь для людей и в шинели ходишь, да и сапоги, пожалуй, для них же носишь. Сапоги в таком случае, маточка, душечка вы моя, нужны мне для поддержки чести и доброго имени; в дырявых же сапогах и то и другое пропало, поверьте, маточка, опытности моей многолетней поверьте; меня, старика, знающего свет и людей, послушайте, а не пачкунов каких-нибудь и марателей» («Бедные люди», 76); Символическое значение сапог как знака достатка, положения в обществе раскрывается и в других текстах Достоевского, причем разных жанров. (2) Характерно использование Достоевским символических жестов чистить, целовать, подавать, снимать сапоги кому-л., отражающих иерархические отношения, нахождение в подчинении у кого-л.: [Федька Каторжный П. Верховенскому] «Ты постой, Пётр Степанович, постой, щеголевато отчеканивая каждое слово, заговорил он, - ты первым долгом здесь должен понимать, что ты на благородном визите у господина Кириллова, Алексея Нилыча, у которого всегда сапоги чистить можешь, потому он пред тобой образованный ум, а ты всего только - тьфу!» (Бесы, 427); (3) Сапоги как символ материального, приземленного, низкого в оппозиции духовному, высокому раскрывается также в следующих контекстах: [Хроникер] «На последнем чтении своем он [C. Т. Верховенский] задумал подействовать гражданским красноречием, воображая тронуть сердца и рассчитывая на почтение к своему “изгнанию”. Он бесспорно согласился в бесполезности и комичности слова "отечество”; согласился и с мыслию о вреде религии, но громко и твердо заявил, что сапоги ниже Пушкина, и даже гораздо (Бесы, 23); Мне кажется, он [Смердяков] никого не любил, кроме себя, уважал же себя до странности высоко. Просвещение видел в хорошем платье, в чистых манишках и в вычищенных сапогах («Братья Карамазовы». Т. II, 165) (4) Hademые сапоги могут символизировать готовность к совершению какого-л. поступка (начало пути и др.): [Хроникёр] «Упомяну лишь, что в это утро он [С. Т. Верховенский] был уже в лихорадке, но и болезнь не остановила его: он твердо шагал по мокрой земле; видно было, что обдумал предприятие как только мог это сделать лучше один при всей своей кабинетной неопытности. Одет был «по-дорожному», то есть шинель в рукава, а подпоясан широким кожаным лакированным поясом с пряжкой, при этом высокие новые сапоги и панталоны в голенищах» (Бесы, 411); (5) Сапог, сапоги - место, куда можно спрятать деньги или орудие убийства (аналогично бритве, обмотанной шелком в романе «Идиот»): [Ракитин А. Карамазову] «Ведь в вашем семействе сладострастие до воспаления доведено. Ну вот эти три сладострастника друг за другом теперь и следят... с ножами за сапогом» (Братья Карамазовы. Т. I, 74); (6) Символическая функция идиоглоссы canoz, сапоги связана также с ключевым для Достоевского концептом 
'страх' (страх не быть принятым в обществе, разоблачения и др.): [Раскольников о себе] «Стало быть, не оставил же еще совсем разум, стало быть, есть же соображение и память, коли сам спохватился и догадался! - подумал он с торжеством, глубоко и радостно вздохнув всею грудью, - просто слабосилие лихорадочное, бред на минуту», - и он вырвал всю подкладку из левого кармана панталон. В эту минуту луч солнца осветил его левый сапог: на носке, который выглядывал из сапога, как будто показались знаки. Он сбросил сапог: “действительно знаки! Весь кончик носка пропитан кровью”; должно быть, он в ту лужу неосторожно тогда ступил..» («Преступление и наказание», 72).

Текстовое ассоциативное поле (о возможностях и процедуре его реконструкции см. [Конкина, Ружицкий, 2016; Ружицкий, Ма Цзинян, 2021]), ядром которого является идиоглосса сапог, сапоги, отражено прежде всего в зонах АССЦ, СЧТ1 и СЧТ2 комментария словарной статьи:

АССЦ бедно, белое пятно, блестеть, блик, ветошка, вспоминать, вспомнить, галстух, готовность, грязь, жилетка, замазывать дырочки чернилами, казна, кланяться, кровь, лопнуть, лужа, луч солнца, материализм, менять, мостовая, на цыпочках, надевать, найти что-нибудь смешное, нижнее платье, ноги, обтирать, одет очень скверно, отсвечивать, пинок, подошва, порог, поэты, приятно, происхождение, прохожие, Пушкин, разглядывать, рубль серебром, служанка, служба, служить, сниться, ступить, сшить, тротуар, тряпка, уйти, унижать, утро, шинель.

СЧТ1 (выборочно) сапог военный, вычищенный, генеральский, тонкий щегольский, огромный грубый, огромный смазной, покинутый своею калошею, старый, закорузлый, весь облепленный засохшею грязью, дырявый; сапоги высокие новые, вычищенные петербургские, дырявые, изъянившиеся, казенные, мягкие неслышные, похожие больше на туфли, чем на сапоги; пудовые; скверные, почти мужицкие; смазные, чиновничьи; сапоги в каких особенно любят щеголять маленькие детки, которых балуют зажиточные отцы; сапоги его превосходительства, сановников; сапоги без подмёток, в грязи без калош, в заплатках, с блестящими гусарскими голенищами, с большими красными отворотами, с кисточками, с оторочкой; сапоги в дорогу; сапоги сапогам рознь; сапог бросился в глаза, осиротел; сапоги были уж полтора года в дырьях, вздор, вознесены были, во всяком случае лучше Пушкина, всю ночь снились, гармонировали с его жалкой одеждой; из сапога выглядывать [о носке, пропитанном кровью], торчать [о голых пальцах]; сапогу поклониться; сапоги сапогам рознь; сапоги беречь, выучиться носить, завести, занимать, заставлять подавать, заставлять снимать, целовать; как старые сапоги менять; в сапог припрятать; в сапоги запрятываться; на сапоги [с любовью] взглядывать, дать свои последние три целковых, сапогом колотить [в двери], постукивать, пристукнуть; сапогом пинок; с худыми сапогами голодать; в сапоге нож припасен; в сапогах обшаривать...

СЧТ2 (выборочно) без шинели и без сапогов ходить; сапоги, панталоны и весь левый бок его были совершенно в грязи; дырявые сапоги, засаленная фуражка; завести себе сапоги и шинелишку; можно даже и сапоги купить, и костюм поправить; смешное нашли или насчёт сапогов моих - именно насчёт сапогов; явился ровно в одиннадцать часов, прямо от обедни, во фраке, прилично заштопанном, и действительно в новом жилете и в новых сапогах; Да и сапоги-то у меня больно худы, маточка, да и пуговок нет... да того ли еще нет у меня!; предстал весь изорванный, в грязной одежде, в грязных сапогах...

Особо отмечаются случаи употребление слова сапоги в составе зевгмы:

$<\ldots>$ наконец, некто Толкаченко - странная личность, человек уже лет сорока и славившийся огромным изучением народа, преимущественно мошенников и разбойников, ходивший нарочно по кабакам (впрочем - не для одного изучения народного) и щеголявшим между нами дурным платьем, смазными сапогами, прищуренно-хитрым видом и народными фразами с завитком (Бесы, 302); Всё недоумение лишь в том, что прекраснее Шекспир или сапоги, Рафаэль или петролей? 
И. В. Ружицкий, М. М. Коробова. Лексикографическое представление лексемы «сапоги» в Идиоглоссарии Достоевского

(Бесы, 372); За ширмами жил некий муж, по прозвищу Млекопитаев; он целую жизнь искал себе места и целую жизнь голодал с чахоточной женою, с худыми сапогами и с голодными пятерыми детьми (Публицистика).

В зонах СЧТ1 и СЧТ2 комментария словарной статьи наиболее явно отражаются идиостилевые особенности употребления описываемой идиоглоссы, ее индивидуально-авторские особенности.

Для лексикографического представления идиоглоссы сапог, сапоги релевантными также являются зоны МРФ, ИРОН, ТРП, ЧЖР и СЛБР комментария.

Материалы словарной статьи сапог, сапоги позволяют сделать несколько выводов и высказать множество предположений: об эмблематической и символической функции этой идиоглоссы, аналогичной гоголевской шинели; о важности для Достоевского вообще какой-либо детали костюма; о значимости концентрации внимания человека на своей (и - другого) обуви; о корреляции видов сапог и социальной ранжированности, о составе соответствующего текстового ассоциативного поля и других.

Литература

1. Достоевский Ф. М. Полное собрание сочинений в 30 томах. Ленинград: Наука, 1972-1990. Текст: непосредственный.

2. Конкина (Ахметшина) Н. Р., Ружицкий И. В. Зона ассоциаций комментария в словарной статье Словаря языка Достоевского как реконструкция текстового ассоциативного поля // Новая Россия: традиции и инновации в языке и науке о языке. Москва; Екатеринбург: Кабинетный ученый, 2016. С. 119-129. Текст: непосредственный.

3. Коробова М. М. Модель Словаря языка Достоевского: уникальное или универсальное / М. М. Коробова, Е. А. Осокина, И. В. Ружицкий, С. Н. Шепелева // Русский язык за рубежом. 2016. № 5. С. 84-89. Текст: непосредственный.

4. Ружицкий И. В. Язык Достоевского: идиоглоссарий, тезаурус, эйдос: монография. Москва: ЛЕКСРУС, 2015. 543 с. Текст: непосредственный.

5. Ружицкий И. В., Ма Цзинян. Семантическое поле 'страх’ в романе Ф. М. Достоевского «Преступление и наказание»// Вестник МГОУ. Сер. Русская филология. 2021. № 3. С. 48-58. Текст: непосредственный.

6. Словарь языка Достоевского. Лексический строй идиолекта. Т. I / под редакцией Ю. Н. Караулова. Москва: Азбуковник, 2001. 510 с. Текст: непосредственный.

7. СЯД-2008 - Словарь языка Достоевского: Идиоглоссарий. Т. I (А-В) / под редакцией Ю. Н. Караулова. Москва: Азбуковник, 2008. 962 с. Текст: непосредственный.

8. СЯД-2010 - Словарь языка Достоевского: Идиоглоссарий. Т. II (Г-3) / под редакцией Ю. Н. Караулова. Москва: Азбуковник, 2010. 1049 с. Текст: непосредственный.

9. СЯД-2017 - Словарь языка Достоевского: Идиоглоссарий. T. IV (Н-По) / под редакцией Ю. Н. Караулова; научный редактор И. В. Ружицкий. Москва: Азбуковник, 2017. 859 с. Текст: непосредственный.

10. СЯД-2021 - Словарь языка Достоевского: Идиоглоссарий. Т. V (По-С) / под редакцией Ю. Н. Караулова; научный редактор И. В. Ружицкий. Москва: Азбуковник, 2021. 1250 с. (в печати).

Статья поступила в редакцию 19.09.2021; одобрена после рецензирования 15.10.2021; принята к публикации 29.10.2021. 
LEXICOGRAPHIC REPRESENTATION

OF THE LEXICAL ITEM САПОГИ 'BOOTS'

IN DOSTOEVSKY'S IDIOGLOSSARY

Igor V. Ruzhitsky

Dr. Sci. (Phil.), Prof. of Department of Didactic Linguistics

and Teaching Russian as a Foreign Language,

Lomonosov Moscow State University

1/51 Leninskie Gory, Moscow 119991, Russia

konnitie@mail.ru

\section{Marina M. Korobova}

Research Assistant of Experimental Lexicography Department, Vinogradov Russian Language Institute RAS

18/2 Volkhonka St., Moscow 119019, Russia

mmkor1955@yandex.ru

Abstract. The article shows the possibility of a dictionary description of the lexical item canozu 'boots', which functions in Dostoevsky's texts as an idioglossa, i. e. the word that reflects the features of the author's idiostyle. We have briefly described the system of lexicographic parameters underlying the structure of the Dostoevsky Language Dictionary, as well as its basic part - Idioglossary, which includes the parataxis and hypotaxis of the described word, its use in the same context with the root words, symbolic use, the composition of the text associative field, etc. We also have determined and illustrated by examples from Dostoevsky's texts the most relevant idioglossas and parameters for lexicographic representation of the word canozu 'boots'. The article draws conclusions about the possibilities of interpreting the obtained lexicographic data primarily in terms of the symbolic and emblematic functions of the described lexical item, and the corresponding text associative field.

Keywords: Dostoevsky, dictionary of the writer's language, idioglossary, structure of the dictionary entry, lexicographic parameterization, idioglossa.

For citation

Ruzhitsky I. V., Korobova M. M. Lexicographic Representation of the Lexical Item canozu 'boots' in Dostoevsky's Idioglossary. Bulletin of Buryat State University. Philology. 2021; 3: 38-44 (In Russ.).

The article was submitted 19.09.2021; approved after reviewing 15.10.2021; accepted for publication 29.10.2021. 